\title{
Variation in Floral Scent Compositions of Different Lily Hybrid Groups
}

\author{
Ying Kong, Jinrong Bai ${ }^{1}$, Lixin Lang, Fang Bao, Xiaoying Dou, Huan Wang, and \\ Hongzhong Shang \\ Department of Plant Research, Beijing Radiation Center, Beijing 100015, China; and Key Lab of \\ Beam Technology and Material Modification of Ministry of Education, College of Nuclear Science \\ and Technology, Beijing Normal University, Beijing 100875, China
}

\begin{abstract}
AdDitional index words. Lilium, volatile compound, pedigree
Abstract. Lilium cultivars have a wide range of variation in floral scent phenotypes. Using gas chromatography-mass spectrometry (GC/MS) analyses of volatile emissions during the night, the floral scent compositions of 35 lily cultivars from seven different hybrid groups were studied. The results showed that there was a positive correlation between volatile emission levels and scent intensities. Nonscented lily cultivars belonging to Asiatic hybrids hardly emitted volatiles, light-scented Longiflorum $\times$ Asiatic hybrids emitted low levels of volatiles, and scented lily cultivars (belonging to Oriental, Trumpet, Longiflorum, Longiflorum $\times$ Oriental, and Oriental $\times$ Trumpet hybrids) emitted significantly high levels of volatiles. In general, the scent compositions of lily cultivars were similar within the same hybrid group, and the differences among hybrid groups reflect their pedigree. Monoterpenoids and benzenoids dominated the floral scents of most volatile-emitting lily cultivars, whereas monoterpenoids alone dominated the floral scents of some volatile-emitting lilies. Although various scent compounds were released from volatile-emitting lily cultivars, the dominant scent compounds were focused on three monoterpenoids [1.8-cineole, linalool, and (E)- $\beta$-ocimene] and one benzenoid (methyl benzoate). The scent traits of lily cultivars could be traced back to their parents.
\end{abstract}

Lily is an important and popular cut flower and potted plant in the floriculture industry (van Tuyl et al., 2011; Zhou et al., 2008). The genus Lilium, including $\approx 100$ species, was classified botanically into seven sections: Martagon, Pseudolirium, Lilium, Archelirion, Sinomartagon, Leucolirion, and Oxypetalum (De Jong, 1974), which are the ancestors of modern lily cultivars (McRae, 1998). More than 10,000 lily cultivars with varied color, size, shape, and scent have been bred and registered (Younis et al., 2014). These cultivars were classified into nine horticultural divisions by the Royal Horticultural Society (2012). Among these divisions, the Asiatic, Oriental, and Longiflorum hybrids were originated from intrasection crosses within Sinomartagon, Archelirion, and Leucolirion, respectively (Zhou et al., 2012). The Trumpet hybrids were originated from crossing within some trumpet lily species (belonging to section Leucolirion) and L. henryi. With the development of pollination techniques, embryo rescue, and polyploidization methods, many intersection hybrids, such as the LA (Longiflorum $\times$ Asiatic), $\mathrm{LO}$ (Longiflorum $\times$ Oriental), and OT (Oriental $\times$ Trumpet) hybrids, have been bred with superior growth vigor and plant habits (van Tuyl and Arens, 2011). Lily cultivars have different floral scent traits, for example, most Asiatic hybrids are scentless, whereas the Oriental and OT hybrids are fragrant.

Floral scent is an important trait of ornamental flowers and cut flowers (Chandler and Brugliera, 2011; Kishimoto et al., 2013, 2014). The sensory qualities of ornamental flowers have

Received for publication 25 Oct. 2016. Accepted for publication 13 Mar. 2017. This work was supported by the 12th Five Years Key Programs for Science and Technology Development of China (2013BAD01B0706), the Program for Innovative Research Team in BJAST (IG201404N), and the BJAST Young Researcher Training Plan (201416).

${ }^{1}$ Corresponding author. E-mail: bjr301@126.com. major impact on consumer preference (Zhang et al., 2014). Floral scent is a complex mixture of low molecular weight volatiles, including terpenoids (monoterpenoids and sesquiterpenoids), phenylpropanoids, benzenoids, fatty acid derivatives, and amino acid derivatives (Widhalm et al., 2015; Xiang et al., 2007). In nature, the key role of floral scent is to attract pollinators for reproductive success (Fenske and Imaizumi, 2016; Muhlemann et al., 2014; Yue et al., 2015). It has also been highly appreciated by humans for its fragrance and health benefits (Jo et al., 2013; Lücker et al., 2006).

Scent is a highly marketable trait with increasing commercial interest in floriculture (Pichersky and Dudareva, 2007; Xiang et al., 2007). Especially because many cut flowers such as rose (Rosa sp.) and carnation (Dianthus sp.) have little to no scent compared with wild species (Chandler and Tanaka, 2007; Kishimoto et al., 2013). But the strong fragrance of many lily cultivars is peculiar. Some people enjoy the lily scent, and others strongly dislike it (McCulloch, 2015). It is often initially pleasant, but can become overwhelming with longer periods of exposure. Applications of aminooxyacetic acid (AOA) have successfully reduced lily scent production by inhibiting the biosynthesis of aromatics. When added in the vase solution of the oriental lily 'Casa Blanca', AOA lowered emissions and rendered the fragrance milder and more pleasant (OyamaOkubo et al., 2011). Therefore, it would be highly advantageous to breed new lily cultivars with an optimal level of scent and identify the genes involved in scent production for future breeding and genome editing efforts.

This task is hindered by a lack of floral scent research in lily. Previous studies on Lilium species and lily cut flowers demonstrated that scented lilies showed a nocturnal emission pattern, and their major volatiles were monoterpenoids and benzenoids, with the tepals as the source of floral scent (Kong et al., 2012, 2013; Morinaga et al., 2009; Oyama-Okubo et al., 2011). A 
detailed volatile profile for a large group of cultivars has not yet been undertaken.

In this study, we measured the volatile profiles of 35 cultivars belonging to seven main hybrid groups (Asiatic, Oriental, Longiflorum, Trumpet, LA, LO, and OT hybrids), which revealed the scent variations within and among different hybrid groups. This research will provide a more comprehensive understanding of lily cultivars' fragrance, and the origins of lily scent will be discussed.

\section{Materials and Methods}

Plant materials. Bulbs of 34 lily cultivars from seven main hybrid groups were purchased from the Netherlands by Sino Floriculture Co. (Lianyungang, China) and Beijing Plant Horticulture Co. (Beijing, China). They were grown in the field of lily germplasm garden [Taipingzhuang, Beijing, China (lat. $40^{\circ} 16^{\prime} \mathrm{N}$, long. $116^{\circ} 42^{\prime} \mathrm{E}$ )] in early April under natural conditions. The seeds of 'Augusta' were purchased from Japan by Zhejiang Hongyue Seed Co. (Jiaxing, China) and sown in a greenhouse in last November. After 3 months' growth, the seedlings were also cultivated in the field of lily germplasm garden. The fields were irrigated weekly, and the flowering period was from late May to August. During the summer, the Oriental hybrids were provided protection from the hot summer sun. Experiments were conducted from June to July in 2013 and 2014. Upon flowering, the fully opened flowers (1 d after anthesis) in the basal part of the inflorescences were chosen for volatile analyses. Their scent intensity was evaluated and graded (scented, light-scented, and nonscented) by five authors before sampling volatiles referring to the scent evaluation on tulips [Tulipa sp. (Oyama-Okubo and Tsuji, 2013)]. The floral characteristics of 35 lily cultivars used for scent analyses are listed in Table 1.

SCEnT SAMPLing. The flower volatiles were sampled based on the descriptions of Kong et al. (2012) with minor modifications on sampling time and volume. Between 2100 and $2300 \mathrm{HR}$, the sampled flower was cut with 1-cm-long peduncle, anthers were removed carefully and then immediately enclosed within an oven bag $(406 \times 444 \mathrm{~mm}$; Reynolds, Richmond, VA)

Table 1. Cultivar names, codes, and their floral characteristics of 35 tested lilies used for floral volatile analysis.

\begin{tabular}{|c|c|c|c|c|c|c|}
\hline Groups & Cultivar & Code & Floral scent & Flower color & Flower diam $(\mathrm{cm})$ & $\begin{array}{l}\text { Tepal fresh wt } \\
{[\text { mean } \pm \text { SE }(g)]^{z}}\end{array}$ \\
\hline \multirow[t]{8}{*}{ Oriental hybrids } & Camengo & Cam & Scented & Light pink & $15.5-17.5$ & $4.94 \pm 0.15$ \\
\hline & Cassini & Cas & Scented & Deep pink & $16.5-18.0$ & $4.54 \pm 0.33$ \\
\hline & La Mancha & La & Scented & Pink & $15.0-16.5$ & $3.51 \pm 0.32$ \\
\hline & Lombardia & Lom & Scented & Pink & $16.0-18.5$ & $5.54 \pm 0.17$ \\
\hline & Mero Star & Mer & Scented & Deep pink & $14.0-15.0$ & $4.81 \pm 0.09$ \\
\hline & Rialto & Ria & Scented & White & $15.0-16.5$ & $3.92 \pm 0.32$ \\
\hline & Starfighter & Sta & Scented & Deep pink with white edges & $12.5-15.5$ & $3.57 \pm 0.27$ \\
\hline & White Proud & WPd & Scented & White & $12.5-13.0$ & $3.48 \pm 0.23$ \\
\hline \multirow[t]{4}{*}{ Trumpet hybrids } & African Queen & Afr & Scented & Orange & $12.0-16.0$ & $12.70 \pm 1.68$ \\
\hline & Pink Planet & $\mathrm{PPt}$ & Scented & Light pink & $12.0-14.0$ & $16.64 \pm 2.24$ \\
\hline & Regale & Reg & Scented & White with yellow throat & $11.6-12.0$ & $12.15 \pm 0.23$ \\
\hline & Yellow Planet & Yel & Scented & Yellow & $14.0-16.0$ & $15.13 \pm 0.75$ \\
\hline \multirow[t]{2}{*}{ Longiflorum hybrids } & White Present & WPt & Scented & White & $16.5-18.5$ & $23.48 \pm 1.23$ \\
\hline & Augusta & Aug & Scented & White & $10.0-11.0$ & $7.53 \pm 0.76$ \\
\hline \multirow{9}{*}{$\begin{array}{l}\text { Oriental } \times \text { Trumpet } \\
(\text { OT) hybrids }\end{array}$} & Donato & Don & Scented & Deep pink & $17.5-19.5$ & $14.01 \pm 1.44$ \\
\hline & Judith Saffigna & Jud & Scented & Deep pink with white edges & $13.0-14.0$ & $15.12 \pm 0.69$ \\
\hline & Manissa & Man & Scented & Yellow with white edges & $19.0-20.0$ & $25.26 \pm 2.54$ \\
\hline & Mussasi & Mus & Scented & Deep pink & $15.0-16.0$ & $11.03 \pm 0.74$ \\
\hline & Pink Palace & $\mathrm{PPe}$ & Scented & Pink & $16.5-18.0$ & $11.25 \pm 0.37$ \\
\hline & Profundo & Pro & Scented & Deep pink & $18.5-19.0$ & $16.11 \pm 0.22$ \\
\hline & Revelation & Rev & Scented & White & $17.0-18.0$ & $13.97 \pm 0.77$ \\
\hline & Robina & Rob & Scented & Deep pink & $15.5-17.5$ & $13.58 \pm 0.68$ \\
\hline & Tabledance & $\mathrm{Tab}$ & Scented & Pink & $16.7-18.0$ & $10.52 \pm 0.88$ \\
\hline \multirow{2}{*}{$\begin{array}{l}\text { Longiflorum } \times \text { Oriental } \\
\text { (LO) hybrids }\end{array}$} & Triumphator & Tri & Scented & White with pink throat & $15.0-16.0$ & $13.66 \pm 0.37$ \\
\hline & White Triumph & WTh & Scented & White & $15.0-15.5$ & $11.51 \pm 0.69$ \\
\hline \multirow{5}{*}{$\begin{array}{l}\text { Longiflorum } \times \text { Asiatic } \\
(\text { LA) hybrids }\end{array}$} & Couplet & Cou & Light-scented & Light pink & $13.5-15.0$ & $6.31 \pm 0.19$ \\
\hline & Desiderio & Des & Light-scented & Orange & $17.0-18.0$ & $10.75 \pm 0.60$ \\
\hline & Eyeliner & Eye & Light-scented & White & $16.6-17.0$ & $11.37 \pm 0.45$ \\
\hline & Orange Tycoon & Ora & Light-scented & Orange & $15.5-17.0$ & $11.06 \pm 1.39$ \\
\hline & Serrada & Ser & Light-scented & Yellow & $16.0-17.0$ & $10.40 \pm 0.99$ \\
\hline \multirow[t]{5}{*}{ Asiatic hybrids } & Benfica & Ben & Nonscented & Orange & $15.3-15.8$ & $7.20 \pm 0.43$ \\
\hline & Nello & Nel & Nonscented & Red & $15.8-16.0$ & $7.20 \pm 0.63$ \\
\hline & Navona & $\mathrm{Nav}$ & Nonscented & White & $15.0-16.0$ & $6.74 \pm 0.21$ \\
\hline & Pollyanna & Pol & Nonscented & Yellow with orange throat & $17.5-18.5$ & $4.76 \pm 0.42$ \\
\hline & Renoir & Ren & Nonscented & Pink & $15.5-16.2$ & $7.52 \pm 0.16$ \\
\hline
\end{tabular}

${ }^{\mathrm{z}}$ Average value of fresh tepals weights from three biological samples. 
(Majetic et al., 2014). After removing the original air, $1.2 \mathrm{~L}$ $\left(400 \mathrm{~mL} \cdot \mathrm{min}^{-1}\right)$ of air purified by activated carbon was pumped into the bag. After sitting for $6 \mathrm{~min}$, the air containing the volatile compounds was extracted and trapped in an empty adsorbent tube (CAMSCO, Houston, TX) filled with $200 \mathrm{mg}$ adsorbents (Tenax GR, 60/80 mesh; Alltech, Deerfield, IL), using a minipump (GSP-300FT-2; Gastec Corp., Kanagawa, Japan) at a flow rate of $200 \mathrm{~mL} \cdot \mathrm{min}^{-1}$ for $6 \mathrm{~min}$. Controls that consisted of bags without flowers were collected at the same time. For each cultivar, three flowers from different individual plants were sampled and analyzed separately. After sampling, the six tepals were detached and weighed immediately. The adsorbent tubes were kept at $-20^{\circ} \mathrm{C}$ (Jürgens et al., 2009).

GAS CHROMATOGRAPHY-MASS SPECTROMETRY (GC/MS) ANALYSIS. The tubes containing the volatiles were desorbed in an automatic thermal desorber (Turbo Matrix 650; PerkinElmer, Waltham, MA) at $260^{\circ} \mathrm{C}$ for $10 \mathrm{~min}$. Helium flow rate was $1.5 \mathrm{~mL} \cdot \mathrm{min}^{-1}$. The desorbed volatile compounds were first trapped in the cold trap $\left(-25^{\circ} \mathrm{C}\right)$, which was then quickly heated to $300{ }^{\circ} \mathrm{C}$ at a rate of $40{ }^{\circ} \mathrm{C} \cdot \mathrm{s}^{-1}$ and then injected into the $\mathrm{GC}$ through a capillary transfer line at $250{ }^{\circ} \mathrm{C}$. Analysis was performed using a GC (Clarus 600; PerkinElmer) coupled to an MS (Clarus 600T; PerkinElmer). The GC was fitted with a fused-silica capillary column $(30 \mathrm{~m} \times 0.25 \mathrm{~mm} \times 0.25 \mu \mathrm{m}$, DB-5MS; Agilent Technologies, Santa Clara, CA). The GC oven temperature was programmed at $40^{\circ} \mathrm{C}$ for $2 \mathrm{~min}$, then the temperature was increased at a rate of $6^{\circ} \mathrm{C} \cdot \mathrm{min}^{-1}$ to $180^{\circ} \mathrm{C}$, followed by an increase at $15^{\circ} \mathrm{C} \cdot \mathrm{min}^{-1}$ to $270{ }^{\circ} \mathrm{C}$, and finally held at $270{ }^{\circ} \mathrm{C}$ for $3 \mathrm{~min}$. The mass spectra were taken in electron ionization at $70 \mathrm{eV}$, and the mass scan range was 30 to $500 \mathrm{~m} / \mathrm{z}$.

Data analyses. TurboMass 5.4.2 GC/MS software (PerkinElmer) was used for the compound analysis. Compounds were identified by matching the mass spectra with NIST 08 library (National Institute of Standards and Technology, Gaithersburg, MD) or authentic standards when available, then confirmed by comparing the retention index with those in the Pherobase database (El-Sayed, 2016). The proportion of each compound was calculated by dividing the peak area of each compound (after subtracting the background noise) by the sum of all peak areas for a given sample (Majetic et al., 2014). Emission rate of each compound (micrograms of scent per gram fresh tepal weight per $15 \mathrm{~min}$ ) was calculated using peak areas of each compound and the external standard curve when available. An emission level heat map with cluster analysis (maximum linkage, Pearson distance) was created with HemI 1.0 (Deng et al., 2014) to visually compare the volatile emissions. To compare the compound variation, we plotted Venn diagrams using InteractiVenn tool (Heberle et al., 2015) and a nonmetric multidimensional scaling (nMDS) conducted by PAST 3.0 to visualize patterns of variation among samples (Hammer et al., 2001; Suinyuy et al., 2013).

\section{Results and Discussion}

\section{Composition of floral scent emitted from lily cultivars during the night}

In total, 64 volatile compounds were identified from volatileemitting lily flowers, representing more than $99 \%$ of the total detected volatiles. The scented lily cultivars emitted more compounds (29-48 volatiles), whereas light-scented lily cultivars emitted fewer compounds ( $7-13$ volatiles). The nonscented Asiatic hybrids emitted no detectable volatiles. The scent compositions and emission amounts of volatile-emitting lilies are listed in Supplemental Tables 1 and 2 and grouped by their biochemical synthesis pathways (Knudsen et al., 1993). Monoterpenoids alone $(90.74 \%$ to $96.68 \%)$ dominated the floral scents of eight volatile-emitting lily cultivars, including two oriental lily ('Rialto' and 'White Proud'), four OT lilies ('Donato', 'Mussasi', 'Pink Palace', and 'Tabledance'), and two LA lilies ('Eyeliner' and 'Serrada'). Both monoterpenoids (49.65\% to $88.99 \%)$ and benzenoids $(10.75 \%$ to $48.26 \%)$ dominated the floral scents of the other volatile-emitting lily cultivars, except 'Couplet' and 'Desderio' that dominated by monoterpenoids (83.17\% to $88.52 \%)$ and irregular terpenoids $(10.36 \%$ to $12.71 \%)$. Although many volatiles were emitted from lily cultivars, most of them were emitted at a low proportion. The most abundant scent compounds were three monoterpenoids [1.8-cineole, linalool, and $(E)$ - $\beta$-ocimene] and one benzenoid (methyl benzoate).

Irrespective of the Asiatic hybrids' color, no volatiles were emitted or detected during the sampling time. This phenomenon may be caused by their low emission rates that were under the detection limit. The volatile compounds and emissions released from 30 volatile-emitting lilies were compared and clustered (Fig. 1). Although the quantitative and qualitative volatiles varied in different lily cultivars, the scent profiles of lily cultivars within the same hybrid groups were similar except the Trumpet and OT hybrids. These 30 volatile-emitting lily cultivars can be divided into four clades: (A) Oriental hybrids, (B) Trumpet and OT hybrids, (C) Longiflorum and LO hybrids, and (D) LA hybrids. The details of each group are as follows.

Clade A: Oriental hybrids. In total, 36 volatile compounds were identified from eight Oriental hybrids, and 20 compounds were common to all of them. Among these compounds, $(E)-\beta$-ocimene $(0.99 \%$ to $77.84 \%)$, linalool (4.50\% to $55.38 \%)$, and methyl benzoate $(0.27 \%$ to $38.21 \%)$ were the major scent compounds. Some or all of the three compounds dominated the scent compositions. The volatile compounds myrcene $(1.55 \%$ to $4.51 \%),(Z)$-ocimene $(0.39 \%$ to $2.12 \%)$, and benzaldehyde $(0.24 \%$ to $8.30 \%)$ were emitted as minor compounds. In addition, the white flower oriental lilies 'Rialto' and 'White Proud' emitted a smaller proportion of benzenoids $(2.82 \%$ to $3.57 \%)$, which differed from other pink cultivars ( $16.57 \%$ to $48.26 \%$ ) with higher benzenoids emission. It is shown that the emission level of benzenoids might have a negative correlation with anthocyanin absence in Oriental hybrids, which is different from a previous study on white flower oriental lily 'Siberia' that emitted relatively high levels of methyl benzoate (Kong et al., 2012). Further research needs to focus on the relationship between the emission profile and flower color.

Clade B: Trumpet and OT hybrids. Forty-five volatile compounds were identified from four Trumpet hybrids, and 33 of them were common compounds. The four lilies were divided into two subgroups. The volatile composition of 'African Queen' was similar to that of 'Yellow Planet', with the major scent compounds being 1,8-cineole (36.74\% to $49.28 \%$ ), methyl benzoate $(18.48 \%$ to $21.16 \%)$, and $(E)$ - $\beta$-ocimene ( $13.87 \%$ to $26.50 \%)$. The volatile compositions of 'Pink Planet' and 'Regale' were similar, and the major scent compounds were 1,8 -cineole $(68.05 \%$ to $70.85 \%)$ and methyl benzoate $(7.21 \%$ to $11.96 \%)$. Other compounds, including $\alpha$-pinene $(3.01 \%$ to $6.24 \%)$, sabinene $(1.16 \%$ to $2.44 \%)$, $\beta$-pinene 


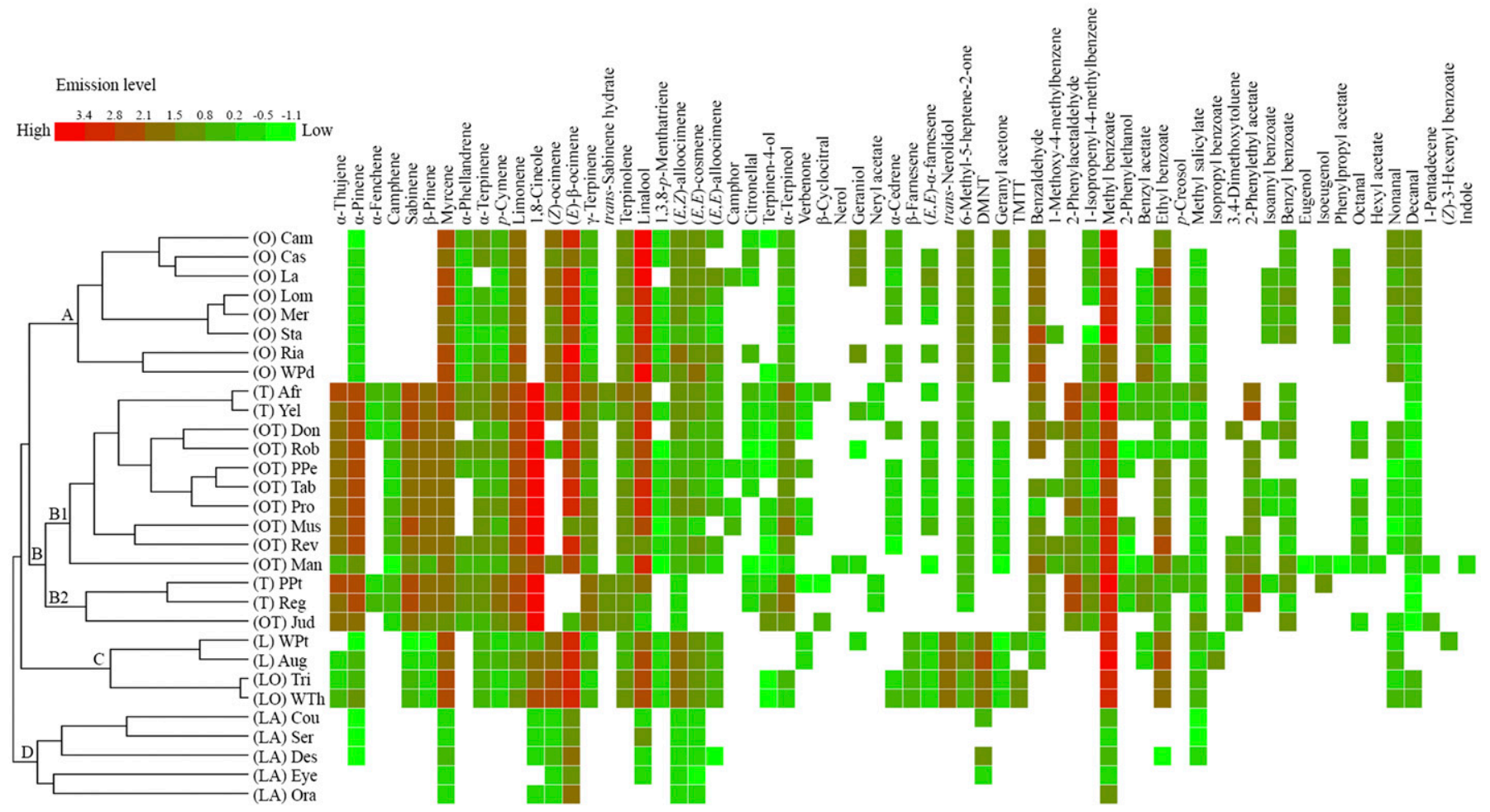

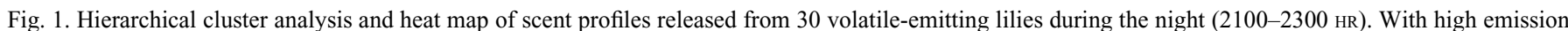
amounts represented as red, low as green, and no emission as blank. The codes for lily cultivars are shown in Table $1 . \mathrm{O}=\mathrm{Oriental}$ hybrids; $\mathrm{T}=\mathrm{Trumpet}$ hybrids; $\mathrm{L}$ $=$ Longiflorum hybrids; OT $=$ Oriental $\times$ Trumpet hybrids; LO $=$ Longiflorum $\times$ Oriental hybrids; LA $=$ Longiflorum $\times$ Asiatic hybrids; DMNT $=(E)-4,8$ dimethylnona-1,3,7-triene; and TMTT $=(E, E)$-4,8,12-trimethyltrideca- 1,3,7,11-tetraene.

$(0.72 \%$ to $1.50 \%)$, myrcene $(0.77 \%$ to $3.15 \%)$, limonene ( $1.17 \%$ to $3.74 \%)$, 2-phenylacetaldehyde $(1.36 \%$ to $2.24 \%)$, and 2-phenethyl acetate $(0.64 \%$ to $1.74 \%)$ were emitted as minor compounds and the last two were the characteristic components.

In total, 57 volatile compounds were identified from nine OT hybrids and 22 compounds were common components. In general, 1,8 -cineole $(7.30 \%$ to $75.32 \%)$, $(E)$ - $\beta$-ocimene $(0.07 \%$ to $20.92 \%)$, linalool $(0.04 \%$ to $57.33 \%)$, and methyl benzoate $(1.81 \%$ to $14.43 \%)$ were the major scent compounds of OT hybrids. Some or all of the four compounds dominated the scent composition. 1,8-Cineole was detected at a high percentage $(44.87 \%$ to $75.32 \%)$ in every OT hybrid except 'Manissa', which emitted high levels of linalool $(57.33 \%)$. Other volatiles, including $\alpha$-pinene $(0.58 \%$ to $5.90 \%)$, sabinene $(0.27 \%$ to $1.59 \%), \beta$-pinene $(0.11 \%$ to $1.50 \%)$, myrcene $(0.64 \%$ to $2.76 \%$ ), and limonene $(1.05 \%$ to $7.83 \%)$ were emitted as minor compounds. Meanwhile, 2-phenylacetaldehyde $(0.04 \%$ to $0.75 \%$ ) was emitted in all OT hybrids, and 2-phenethyl acetate was emitted in some OT hybrids.

So the Trumpet and OT hybrids were clustered together because of their high emission on 1,8-cineole. The differences between Clade B1 and Clade B2 mainly existed in the emission of $(E)$ - $\beta$-ocimene and linalool, in which the former emitted higher $(E)$ - $\beta$-ocimene and linalool.

Clade C: Longiflorum and LO hybrids. There were 31 common compounds of 35 identified compounds in the two tested Longiflorum hybrids. Although $(E)-\beta$-ocimene $(40.11 \%$ to $60.92 \%)$ and methyl benzoate $(19.58 \%$ to $43.80 \%)$ were the major scent compounds, the percentages varied in these two lilies. Meanwhile, myrcene $(2.35 \%$ to $4.59 \%)$, (Z)-ocimene $(1.95 \%$ to $3.70 \%)$, linalool $(2.34 \%$ to $2.92 \%)$, ethyl benzoate $(1.32 \%$ to $2.68 \%)$, trans-nerolidol $(0.65 \%$ to $1.13 \%)$, and (E)-4,8-dimethyl-1,3,7-nonatriene (DMNT, 2.03\% to $2.42 \%$ ) were emitted as minor compounds, and the last two were the characteristic components.

The LO hybrids had similar scent profiles with the Longiflorum hybrids. All of the common 33 volatile compounds were identified in both cultivars, and the two LO hybrids had very similar scent profiles. The major scent compounds were (E)- $\beta$-ocimene $(66.01 \%$ to $67.82 \%)$ and methyl benzoate ( $10.24 \%$ to $11.16 \%)$, whereas myrcene $(4.72 \%$ to $4.84 \%)$, 1,8 -cineole $(1.75 \%$ to $2.35 \%),(Z)$-ocimene $(3.83 \%$ to $4.08 \%)$, linalool $(2.31 \%$ to $4.16 \%),(E, Z)$-alloocimene $(1.82 \%$ to $1.88 \%)$, trans-nerolidol $(1.54 \%$ to $1.71 \%)$, and DMNT (1.48\% to $1.68 \%$ ) were emitted as minor compounds.

Clade D: LA hybrids. Only 13 compounds were identified from the five LA hybrids and 7 of them were common compounds. (E)- $\beta$-ocimene $(46.86 \%$ to $81.03 \%)$ was the common major scent compound and showed the highest percentage. Some lily hybrids emitted high levels of DMNT ('Couplet' and 'Desderio'), methyl benzoate ('Orange Tycoon'), and linalool ('Serrada').

\section{Comparison of emission levels of scented and light-scented lilies during the night}

A detailed analysis performed with the nocturnal emissions of lily cultivars revealed that there was a positive correlation between the total volatile emission levels and the scent intensities. Significantly high levels of volatiles [3.80-20.77 $\mu \mathrm{g} \cdot \mathrm{g}^{-1}$ 
fresh weight (FW) per $15 \mathrm{~min}$ ] were emitted from the scented lily cultivars, and low levels of volatiles $\left(0.02-0.11 \mu \mathrm{g} \cdot \mathrm{g}^{-1}\right.$ FW per $15 \mathrm{~min}$ ) were detected in light-scented lilies, whereas no volatiles were detected in nonscented lilies. The comparison of nocturnal emission levels released from 30 volatile-emitting lilies is shown in Fig. 2. Although a wide range of variation within the same hybrid group was shown, the difference in emission levels among groups is clear. The highest emission level of volatiles was found in Trumpet hybrids (13.30-20.77 $\mu \mathrm{g} \cdot \mathrm{g}^{-1} \mathrm{FW}$ per $15 \mathrm{~min}$ ), which was followed by

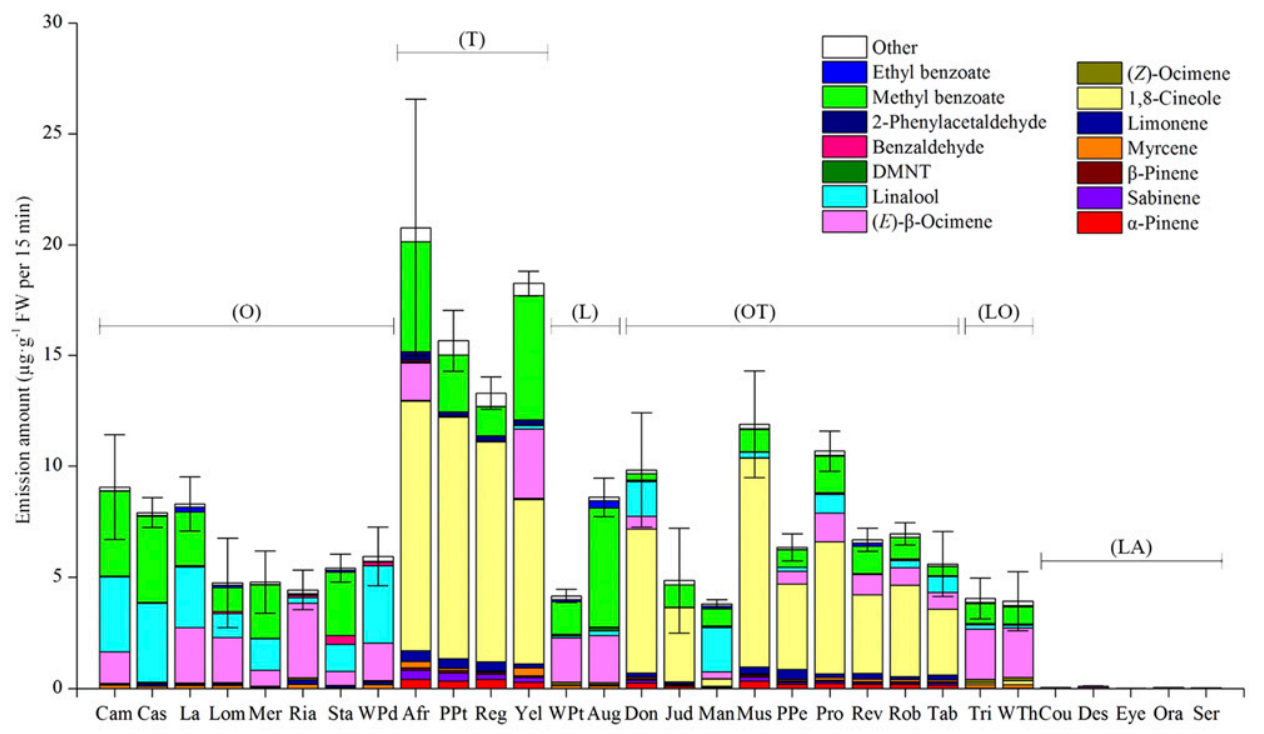

Fig. 2. Comparison of volatile emission levels released from 30 volatile-emitting lilies during the night (21002300 HR). The codes for lily cultivars are shown in Table $1 . \mathrm{O}=$ Oriental hybrids; $\mathrm{T}=$ Trumpet hybrids; $\mathrm{L}=$ Longiflorum hybrids; OT $=$ Oriental $\times$ Trumpet hybrids; LO $=$ Longiflorum $\times$ Oriental hybrids; LA $=$ Longiflorum $\times$ Asiatic hybrids; and DMNT $=(E)$-4,8-dimethylnona-1,3,7-triene.

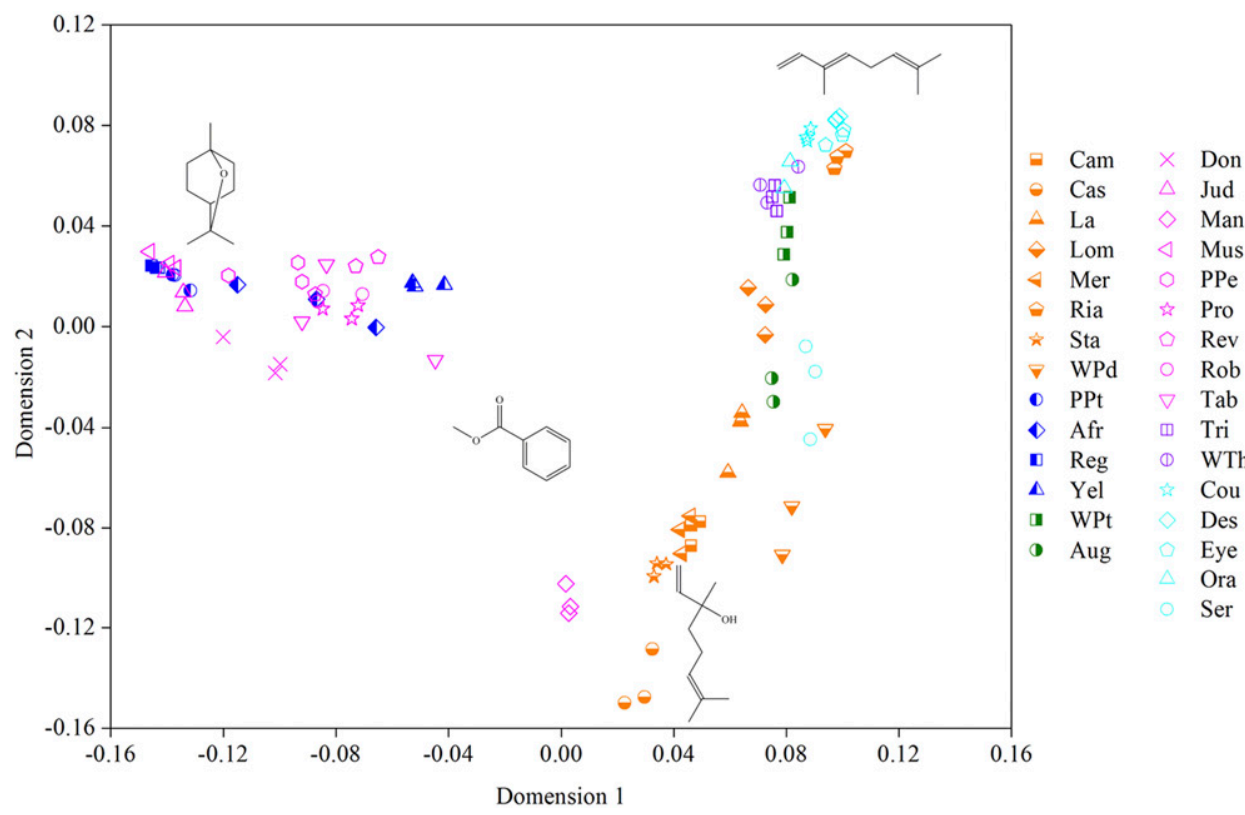

Fig. 3. Nonmetric multidimensional scaling plot, based on the scent compositions of 30 volatile-emitting lily cultivars (Bray-Curtis similarity, stress $=0.09$ ). Cultivars belonging to the same hybrid group are drawn by the same color. The codes for lily cultivars are shown in Table 1 . Blue $=$ Trumpet hybrids; pink $=$ Oriental $\times$ Trumpet hybrids; orange $=$ Oriental hybrids; green $=$ Longiflorum hybrids; violet $=$ Longiflorum $\times$ Oriental hybrids; cyan $=$ Longiflorum $\times$ Asiatic hybrids.
Oriental, Longiflorum, OT, and LO hybrids (3.80-11.90 $\mu \mathrm{g} \cdot \mathrm{g}^{-1}$ FW per $15 \mathrm{~min}$ ). The emission levels of light-scented LA hybrids were significantly lower.

\section{Variation in scent compositions of six lily hybrid groups}

Nonmetric multidimensional scaling was performed to categorize the volatile-emitting lily cultivars based on their vatile compositions (Fig. 3). It is illustrated that the cultivars within the same group were clustered together tightly or loosely. In the three intersection hybrids, the Longiflorums emitted high proportion of $(E)$ $\beta$-ocimene and the Orientals emitted high $(E)$ - $\beta$-ocimene, linalool, or both, whereas the Trumpets emitted high proportion of 1,8-cineole. So the Longiflorums and Trumpets were clustered tightly, whereas the Orientals were clustered loosely and overlapped with the Longiflorums. In the three intrasection hybrids, the LO hybrids were clustered closely and close to Longiflorums. Many LA hybrids with high $(E)$ - $\beta$-ocimene emission were clustered and close to 'White Present', except 'Serrada', which also released high a proportion of linalool. Many OT hybrids overlapped with the Trumpets because of the high 1,8-cineole emission, except 'Manissa' that was closer to Orientals because of the high linalool emission.

\section{Variation in volatile compounds of volatile-emitting lily cultivars}

The volatile products of lily cultivars mainly belonged to two chemical groups (monoterpenoids and benzenoids) and produced by their own biosynthetic pathways. Although many monoterpenoids were emitted, the principal volatiles of lily cultivars were two acyclic monoterpenoids, $(E)$ - $\beta$-ocimene and linalool, and one cyclic monoterpenoid, 1,8cineole (Degenhardt et al., 2009). Some or all of the three compounds accounted for more than $80 \%$ of the total monoterpenoids emission (Fig. 4). It is speculated that one or several monoterpene synthase(s) play an important role in the (mono)terpenoid biosynthetic pathway and thus resulted in different products. Meanwhile, a set of minor monoterpenes were emitted simultaneously in each of the scented lilies, which is likely emitted as minor products of monoterpene synthases (Dudareva et al., 2003; Roeder et al., 2007). Furthermore, other characteristic compounds were produced by their 
specific biosynthetic pathways. The homoterpene DMNT and its regular $\mathrm{C} 15$ precursor $(E)$-nerolidol, which were emitted from Longiflorum and LO hybrids, were produced by other biosynthetic pathways (Tholl et al., 2011). Meanwhile, the biosynthetic pathway where phenylpropanoids (represented by 2-phenylacetaldehyde, 2-phenethyl alcohol, and the acetylated 2-phenylethyl acetate) are produced is different from that where benzenoids (methyl benzoate and benzaldehyde) are produced (Majetic and Sinka, 2013). So the variation in floral scent compounds of lily cultivars was caused by different key genes involved in the same biosynthetic pathways, different metabolic flux, or both among cultivars. Further studies with molecular tools will be helpful for improving our understanding of floral volatile biology.

\section{Relationship and origin of scent traits}

All hybrids exhibit traits that can be traced back to their parents (Balode, 2007; Roh et al., 1996). Like all heritable characteristics, the chemical compounds of floral scents may also reflect their taxonomic affinities (Nogueira et al., 2001). The intrasection hybrid lilies have similar scent traits with their ancestors. For example, most ancestors of Asiatic hybrids have little scent (e.g., L. amabile and L. cernuum) or no scent (e.g., L. dauricum, L. davidii, and L. lancifolium), and L. auratum has similar scent composition with oriental lilies, which showed that it is an important ancestor of scent origin in Oriental hybrids (Kong et al., 2017; McRae, 1998; Morinaga et al., 2009). The scent profiles of Trumpet hybrids were in accordance with their ancestors including $L$. sargentiae, $L$. sulphureum, and $L$. regale, whereas another ancestor $L$. henryi is nonscented and hardly emitted volatiles. The emission difference in $(E)-\beta$-ocimene was also observed in L. sulphureum (Kong et al., 2013, 2017; McRae, 1998). The parentage of 'White Present' is unknown (Royal Horticultural Society, 2012) and presumably derived from $L$. longiflorum, whereas 'Augusta' is an interspecific hybrid derived from L. longiflorum and L. formosanum. This may be the reason for the different scent composition between 'White Present' and 'Augusta'.

The three intersection lily hybrid groups all combined their parents' scent profiles. It is found that the volatiles emitted from LO hybrids also released from both parents (Fig. 5A). The same phenomenon existed in OT hybrids, except that the OT hybrids emitted six specific compounds, which may be due to the true parents of tested OT hybrids that were not included (Fig. 5B). Radar maps based on compositions of four major compounds [1.8-cineole, linalool, $(E)$ - $\beta$-ocimene, and methyl benzoate] emitted from six lily hybrid groups also showed that the LO and OT hybrids combined their parents' scent traits (Fig. 6). In contrast with the nonscented Asiatic hybrids, the LA hybrids with delicate scents may have inherited their scent characteristics from L. longiflorum. All of the scent compounds released from LA hybrids were also found in 'White Present', but the emission was lower, which may be due to their ALA or LAA genome compositions, as in most cases, LA hybrids are triploid (Lim and van Tuyl, 2006; Zhou et al., 2008, 2012).

\section{Conclusions}

This study analyzed the floral fragrances of many lily cultivars with different scent phenotypes. Differences in scent

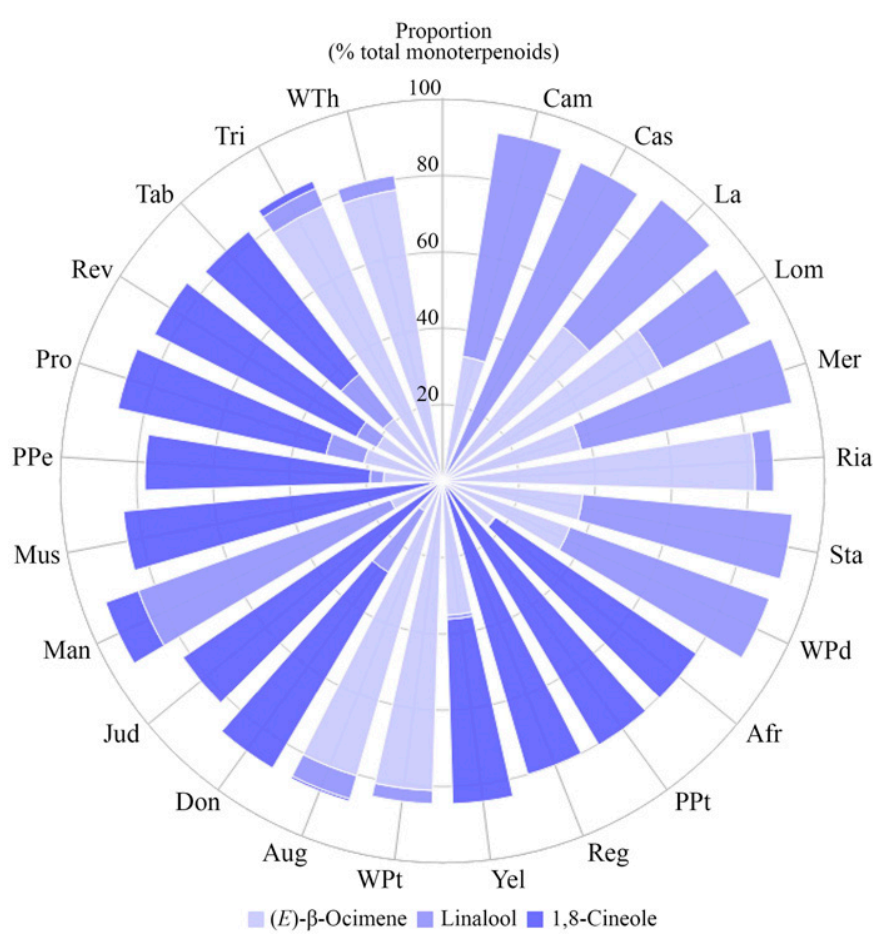

Fig. 4. Stacked radar maps of the proportion of three principal monoterpenoids [linalool, $(E)$ - $\beta$-ocimene, and 1,8-cineole] in the total monoterpenoids emission of scented lilies. The codes for lily cultivars are shown in Table 1 .

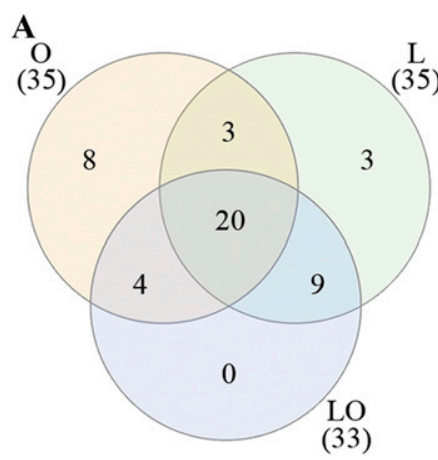

B

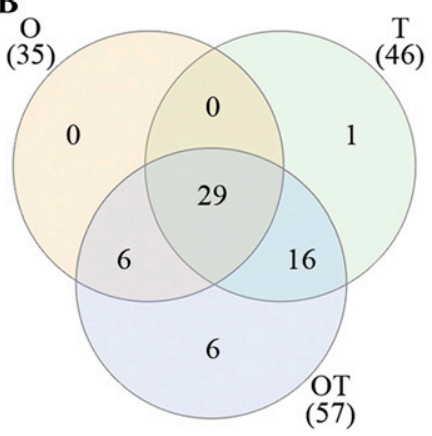

Fig. 5. Venn diagrams indicating the similarities and differences on total volatile compounds among different lily hybrid groups. The numbers in related overlap areas showed that (A) the shared compounds of Oriental hybrids $(\mathrm{O})$, Longiflorum hybrids $(\mathrm{L})$, and Longiflorum $\times$ Oriental hybrids (LO); and (B) the shared compounds of Oriental hybrids (O), Trumpet hybrids $(\mathrm{T})$, and Oriental $\times$ Trumpet hybrids $(\mathrm{OT})$.

intensity was mainly caused by and positively correlated with the volatile emission level. For instance, the nonscented Asiatic hybrids hardly emit volatiles, and light-scented LA hybrids emit low levels of volatiles, whereas scented lily hybrids emit high levels of volatiles. The scent profiles of lily cultivars within the same hybrid groups were similar to some extent, and the differences among hybrid groups reflect their pedigree. The major scent compounds of the Oriental hybrids were $(E)$ - $\beta$-ocimene, linalool, and methyl benzoate, and those of the Trumpet hybrids were 1,8-cineole, methyl benzoate, and $(E)$ - $\beta$-ocimene. The major scent compounds of the Longiflorum and LO hybrids were $(E)$ - $\beta$-ocimene and 
A
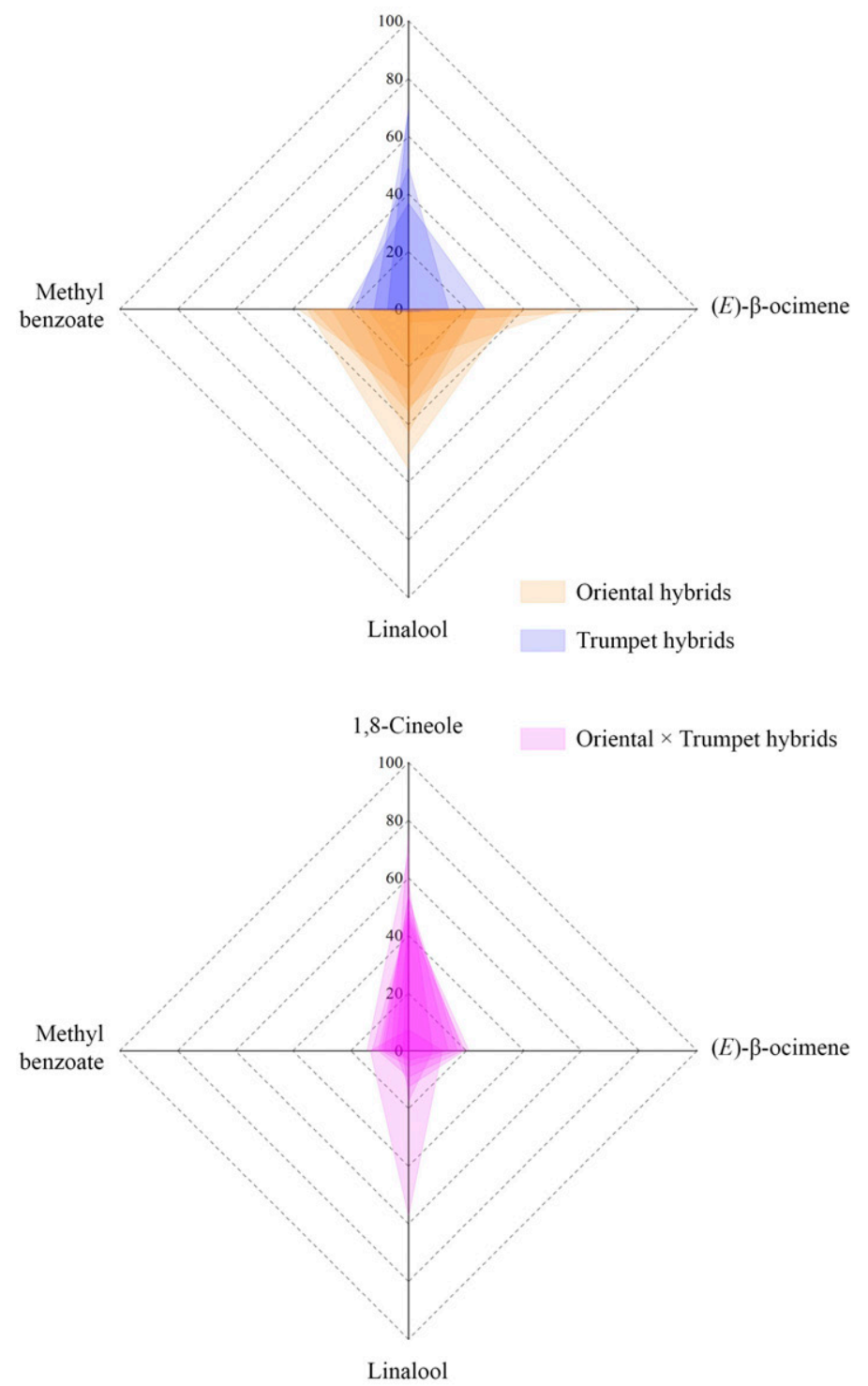

B
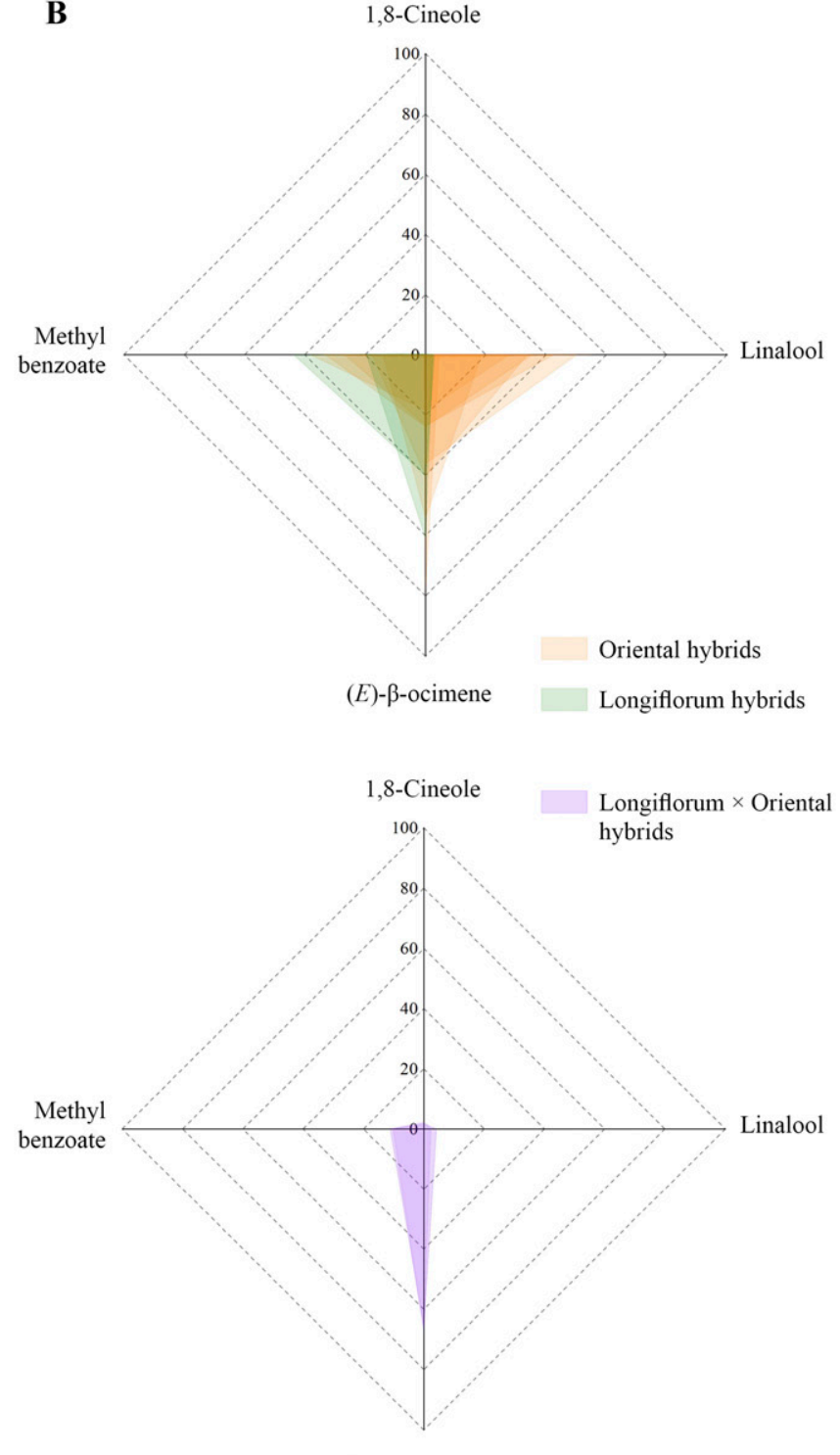

(E)- $\beta$-ocimene

Fig. 6. Radar maps of different lily hybrid groups based on compositions of four major volatiles [1.8-cineole, linalool, $(E)-\beta$-ocimene, and methyl benzoate]. (A) Distribution of Oriental and Trumpet hybrids (up), Oriental $\times$ Trumpet hybrids (down). (B) Distribution of Oriental and Longiflorum hybrids (up), Longiflorum $\times$ Oriental hybrids $($ down).

methyl benzoate, whereas the OT hybrids emitted 1,8 cineole, linalool, $(E)$ - $\beta$-ocimene, and methyl benzoate as major scent compounds. The scent compositions of LA hybrids varied, and $(E)$ - $\beta$-ocimene was the major scent compound. Diverse metabolic pathways and different genes involved in the biosynthetic pathways could contribute to the various scent products. The scent traits of lily cultivars could be traced back to their parents.

It is generally known that most lilies are scented and sometimes overpowering to some people, which may undermine their commercial value (Kishimoto et al., 2014; McCulloch, 2015). Therefore, the regulation of floral fragrance would have a wide range of potential beneficial commercial application. The intersection LA hybrids are good examples of scent modification by interspecific hybridization, and a few other ornamentals' scent traits have been improved by genetic modification (Zuker et al., 2002; Zvi et al., 2012). However, owing to the heterozygosity of the parents and various genes involved in the production of scent compounds (Andargie et al., 2014; Fu et al., 2007; Kishimoto et al., 2013; Spiller et al., 2010), the modification of fragrance is not easy. In the future, combining conventional breeding with molecular breeding techniques would help develop novel lily cultivars with more pleasant floral fragrances.

\section{Literature Cited}

Andargie, M., J.T. Knudsen, R.S. Pasquet, B.S. Gowda, G.M. Muluvi, and M.P. Timko. 2014. Mapping of quantitative trait loci for floral scent compounds in cowpea (Vigna unguiculata L.). Plant Breed. 133:92-100.

Balode, A. 2007. Color analysis of flowers in Lilium sp. breeding. Acta Hort. 755:213-218. 
Chandler, S. and F. Brugliera. 2011. Genetic modification in floriculture. Biotechnol. Lett. 33:207-214.

Chandler, S. and Y. Tanaka. 2007. Genetic modification in floriculture. Crit. Rev. Plant Sci. 26:169-197.

De Jong, P.C. 1974. Some notes on the evolution of lilies. Lily Yrbk. North Amer. Lily Soc. 27:23-28.

Degenhardt, J., T.G. Köllner, and J. Gershenzon. 2009. Monoterpene and sesquiterpene synthases and the origin of terpene skeletal diversity in plants. Phytochemistry 70:1621-1637.

Deng, W., Y. Wang, Z. Liu, H. Cheng, and Y. Xue. 2014. HemI: A toolkit for illustrating heatmaps. PLoS One 9:e111988.

Dudareva, N., D. Martin, C.M. Kish, N. Kolosova, N. Gorenstein, J. Fäldt, B. Miller, and J. Bohlmann. 2003. (E)- $\beta$-Ocimene and myrcene synthase genes of floral scent biosynthesis in snapdragon: Function and expression of three terpene synthase genes of a new terpene synthase subfamily. Plant Cell 15:1227-1241.

El-Sayed, A.M. 2016. The pherobase: Database of pheromones and semiochemicals. 12 Dec. 2016. <http://www.pherobase.com/>.

Fenske, M.P. and T. Imaizumi. 2016. Circadian rhythms in floral scent emission. Front. Plant Sci. 7:462.

Fu, Y., X. Gao, Y. Xue, Y. Hui, F. Chen, Q. Su, and L. Wang. 2007. Volatile compounds in the flowers of Freesia parental species and hybrids. J. Integr. Plant Biol. 49:1714-1718.

Hammer, Ø., D.A.T. Harper, and P.D. Ryan. 2001. PAST: Paleontological statistics software package for education and data analysis. Palaeontol. Electronica 4:9.

Heberle, H., G. Meirelles, F. da Silva, G. Telles, and R. Minghim. 2015. InteractiVenn: A web-based tool for the analysis of sets through Venn diagrams. BMC Bioinformatics 16:169.

Jo, H., S. Rodiek, E. Fujii, Y. Miyazaki, B.J. Park, and S.W. Ann. 2013. Physiological and psychological response to floral scent. HortScience 48:82-88.

Jürgens, A., A.M. El-Sayed, and D.M. Suckling. 2009. Do carnivorous plants use volatiles for attracting prey insects? Funct. Ecol. 23:875887.

Lücker, J., H.A. Verhoeven, L.H.W. van der Plas, and H.J. Bouwmeester. 2006. Molecular engineering of floral scent, p. 321-337. In: E. Pichersky and N. Dudareva (eds.). Biology of floral scent. CRC Press, Boca Raton, FL.

Kishimoto, K., H. Maeda, T. Haketa, and N. Oyama-Okubo. 2014. Odor components and the control of odor development in ornamental cabbage. J. Jpn. Soc. Hort. Sci. 83:252-258.

Kishimoto, K., M. Yagi, T. Onozaki, and H. Yamaguchi. 2013. Analysis of scents emitted from flowers of interspecific hybrids between carnation and fragrant wild Dianthus species. J. Jpn. Soc. Hort. Sci. 82:145-153.

Knudsen, J.T., L. Tollsten, and L.G. Bergström. 1993. Floral scentsa checklist of volatile compounds isolated by head-space techniques. Phytochemistry 33:253-280.

Kong, Y., M. Sun, H. Pan, and Q. Zhang. 2012. Composition and emission rhythm of floral scent volatiles from eight lily cut flowers. J. Amer. Soc. Hort. Sci. 137:376-382.

Kong, Y., M. Sun, H. Pan, Q. Zhang, C. Ai, and Y. Wang. 2013. Floral scent composition of Lilium sulphureum. Chem. Nat. Compd. 49:362-364.

Kong, Y., J. Bai, L. Lang, F. Bao, X. Dou, H. Wang, and H. Shang. 2017. Floral scents produced by Lilium and Cardiocrinum species native to China. Biochem. Syst. Ecol. 70:222-229.

Lim, K.B. and J.M. van Tuyl. 2006. Lily: Lilium hybrids, p. 517-537. In: N. Anderson (ed.). Flower breeding and genetics: Issues, challenges and opportunities for the 21 st century. Springer, Dordrecht, The Netherlands.

Majetic, C.J., D.A. Levin, and R.A. Raguso. 2014. Divergence in floral scent profiles among and within cultivated species of Phlox. Sci. Hort. 172:285-291.

Majetic, C.J. and B.N. Sinka. 2013. Diverging pathways: Differential benzenoid and phenylpropanoid volatile production in Phlox subulata L. cultivars. Biochem. Syst. Ecol. 50:75-81.
McCulloch, M. 2015. Fragrance removal in Lilium L. subdivision Orientalis (Oriental lily). 2 Feb. 2017. <http://hdl.handle.net/11299/ $175840>$.

McRae, E.A. 1998. Lilies: A guide for growers and collectors. Timber Press, Portland, OR.

Morinaga, S.I., Y. Kumano, A. Ota, R. Yamaoka, and S. Sakai. 2009. Day-night fluctuations in floral scent and their effects on reproductive success in Lilium auratum. Popul. Ecol. 51:187-195.

Muhlemann, J.K., A. Klempien, and N. Dudareva. 2014. Floral volatiles: From biosynthesis to function. Plant Cell Environ. 37:1936-1949.

Nogueira, P.C.L., V. Bittrich, G.J. Shepherd, A.V. Lopes, and A.J. Marsaioli. 2001. The ecological and taxonomic importance of flower volatiles of Clusia species (Guttiferae). Phytochemistry 56:443-452.

Oyama-Okubo, N., M. Nakayama, and K. Ichimura. 2011. Control of floral scent emission by inhibitors of phenylalanine ammonialyase in cut flower of Lilium cv. Casa Blanca. J. Jpn. Soc. Hort. Sci. 80:190-199.

Oyama-Okubo, N. and T. Tsuji. 2013. Analysis of floral scent compounds and classification by scent quality in tulip cultivars. J. Jpn. Soc. Hort. Sci. 82:344-353.

Pichersky, E. and N. Dudareva. 2007. Scent engineering: Toward the goal of controlling how flowers smell. Trends Biotechnol. 25:105110

Roeder, S., A.M. Hartmann, U. Effmert, and B. Piechulla. 2007. Regulation of simultaneous synthesis of floral scent terpenoids by the 1, 8-cineole synthase of Nicotiana suaveolens. Plant Mol. Biol. 65:107-124.

Roh, M.S., R.J. Griesbach, K.C. Gross, and M. Line. 1996. Identification and evaluation of the interspecific hybrid between Lilium longiflorum and L. callosum. Acta Hort. 414:111-124.

Royal Horticultural Society. 2012. The international lily register \& checklist (2007). 3rd supplement. Page Bros, Norwich, UK.

Spiller, M., R.G. Berger, and T. Debener. 2010. Genetic dissection of scent metabolic profiles in diploid rose populations. Theor. Appl. Genet. 120:1461-1471.

Suinyuy, T.N., J.S. Donaldson, and S.D. Johnson. 2013. Variation in the chemical composition of cone volatiles within the African cycad genus Encephalartos. Phytochemistry 85:82-91.

Tholl, D., R. Sohrabi, J.H. Huh, and S. Lee. 2011. The biochemistry of homoterpenes - Common constituents of floral and herbivore-induced plant volatile bouquets. Phytochemistry 72:1635-1646

van Tuyl, J.M. and P. Arens. 2011. Lilium: Breeding history of the modern cultivar assortment. Acta Hort. 900:223-230.

van Tuyl, J.M., P. Arens, M.S. Ramanna, A. Shahin, N. Khan, S. Xie, A. Marasek-Ciolakowska, K.B. Lim, and R. Barba-Gonzalez. 2011. Lilium, p. 161-183. In: C. Kole (ed.). Wild crop relatives: Genomic and breeding resources, plantation and ornamental crops. SpringerVerlag, Berlin/Heidelberg, Germany.

Widhalm, J.R., R. Jaini, J.A. Morgan, and N. Dudareva. 2015. Rethinking how volatiles are released from plant cells. Trends Plant Sci. 20:545-550.

Xiang, L., J.A. Milc, N. Pecchioni, and L.Q. Chen. 2007. Genetic aspects of floral fragrance in plants. Biochemistry (Mosc.) 72:351-358.

Younis, A., Y.J. Hwang, and K.B. Lim. 2014. Classical vs. modern genetic and breeding approaches for lily (Lilium) crop improvement: A review. Flower Res. J. 22:39-47.

Yue, Y., R. Yu, and Y. Fan. 2015. Transcriptome profiling provides new insights into the formation of floral scent in Hedychium coronarium. BMC Genomics 16:470.

Zhang, B., Y. Huang, Q. Zhang, X. Liu, F. Li, and K. Chen. 2014. Fragrance discrimination of Chinese Cymbidium species and cultivars using an electronic nose. Sci. Hort. 172:271-277.

Zhou, S., K. Li, and G. Zhou. 2012. Analysis of endosperm development of allotriploid $\times$ diploid/tetraploid crosses in Lilium. Euphytica 184:401-412. 
Zhou, S., M.S. Ramanna, R.G.F. Visser, and J.M. van Tuyl. 2008. Genome composition of triploid lily cultivars derived from sexual polyploidization of Longiflorum $\times$ Asiatic hybrids (Lilium). Euphytica 160:207-215.

Zuker, A., T. Tzfira, H. Ben-Meir, M. Ovadis, E. Shklarman, H. Itzhaki, G. Forkmann, S. Martens, I. Neta-Sharir, D. Weiss, and A. Vainstein.
2002. Modification of flower color and fragrance by antisense suppression of the flavanone 3-hydroxylase gene. Mol. Breed. 9:33-41. Zvi, M.M.B., E. Shklarman, T. Masci, H. Kalev, T. Debener, S. Shafir, M. Ovadis, and A. Vainstein. 2012. PAP1 transcription factor enhances production of phenylpropanoid and terpenoid scent compounds in rose flowers. New Phytol. 195:335-345. 


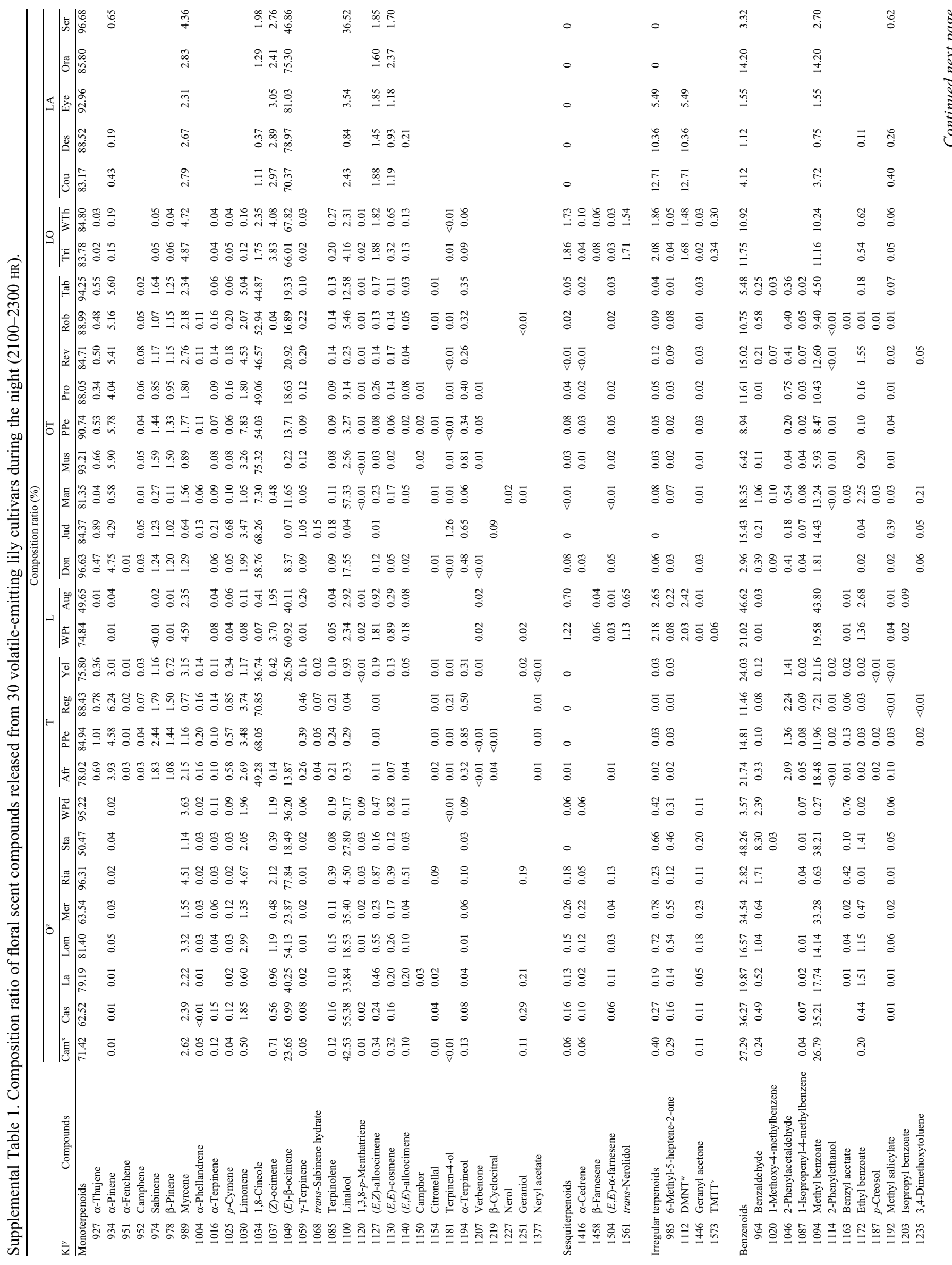




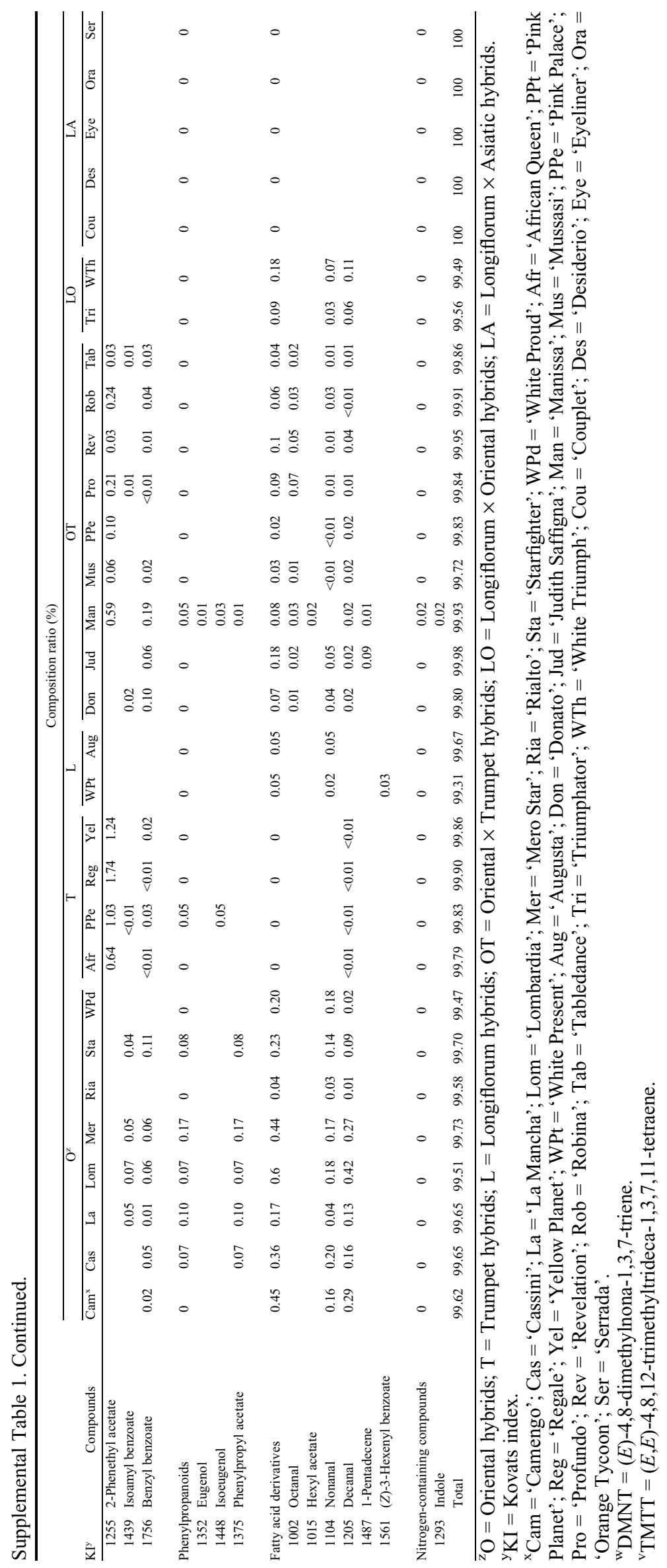




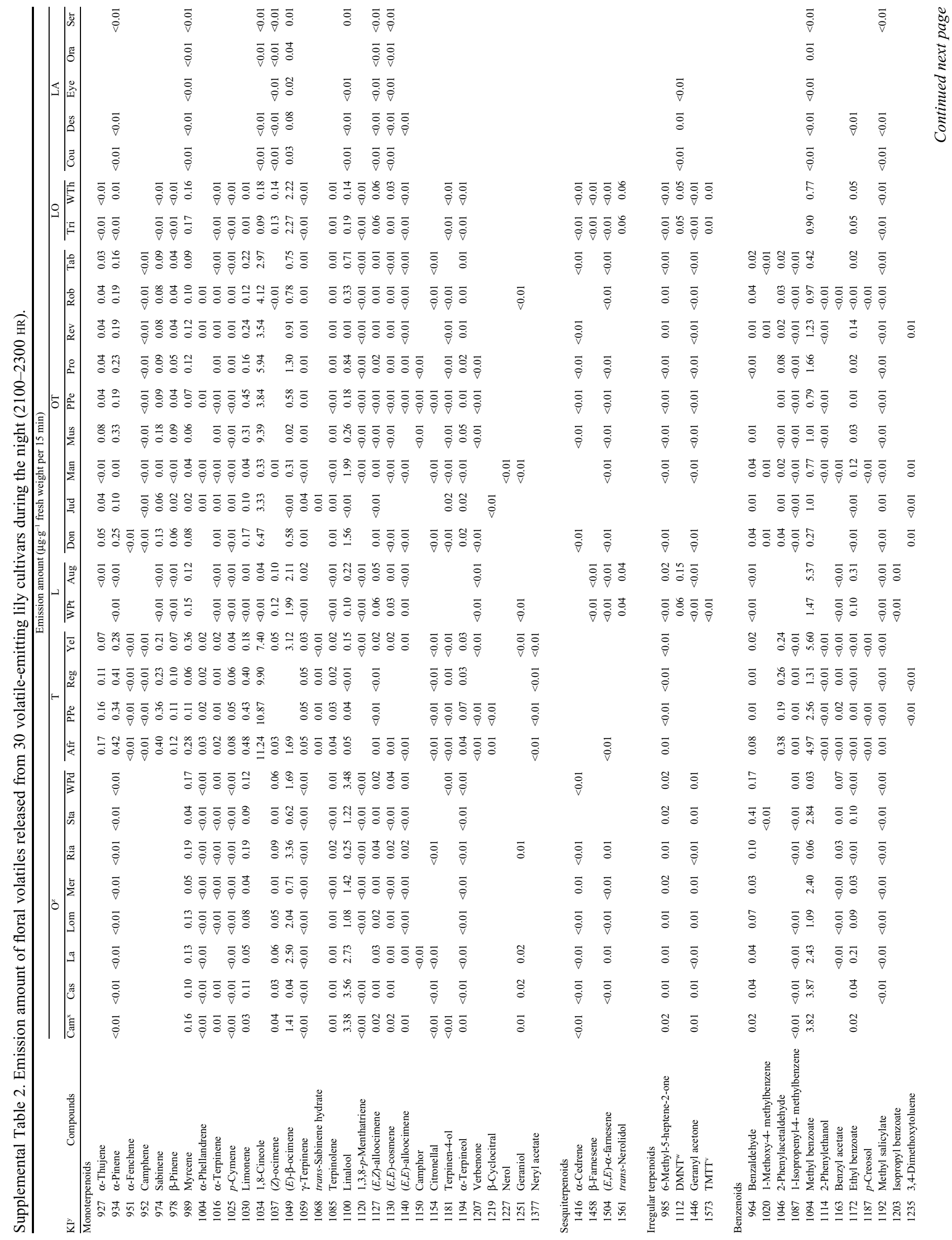




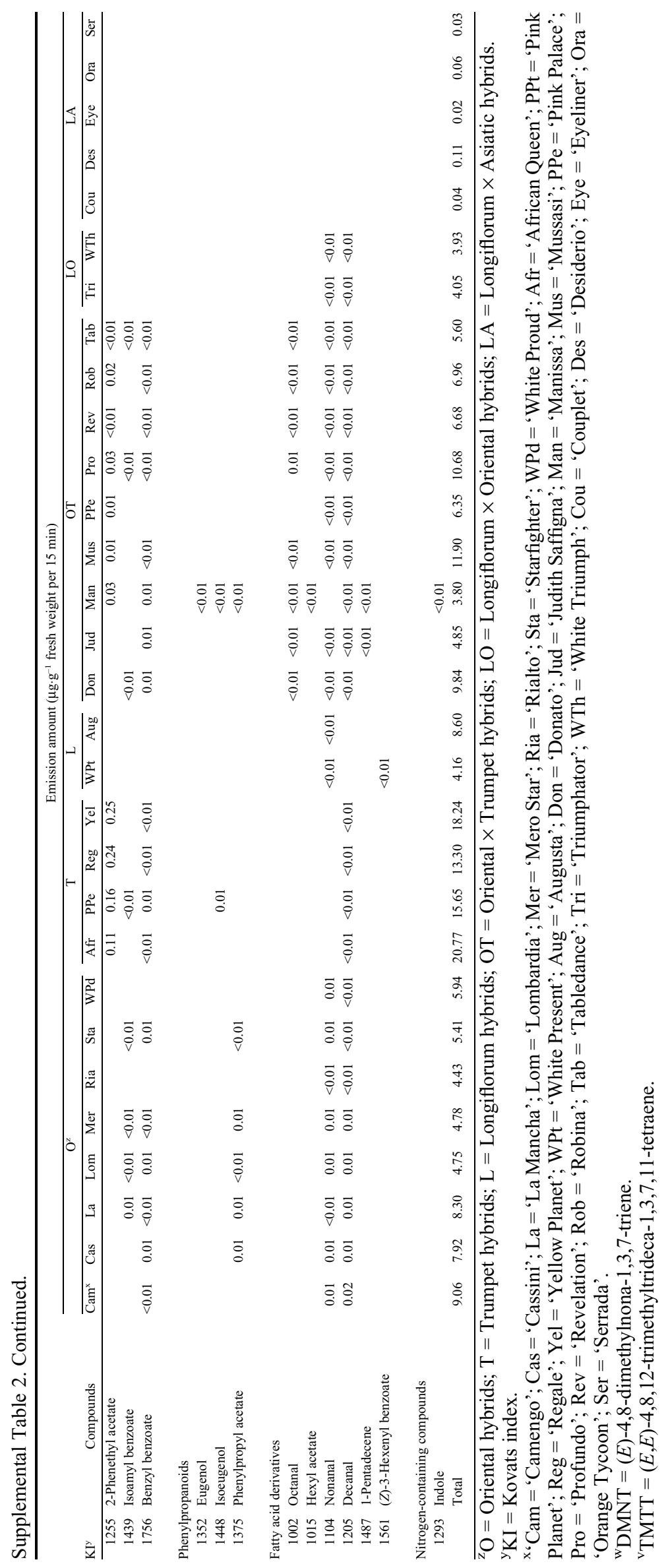

